Received: June 2012

Accepted: December 2012

ISSN $2006-6996$

\title{
NUTRITIONAL STATUS IN PREGNANT WOMEN ATTENDING KIRU GENERAL HOSPITAL IN KANO STATE, NIGERIA
}

Kabiru, T. Hafiz, A. and Atiku, M. K. ${ }^{*}$

Department of Biochemistry, Faculty of Science, Bayero University, PMB 3011, Kano, Nigeria.

*Correspondence author: mkatiku@yahoo.com

\begin{abstract}
The present study determined body weight and height (Body Mass Index-BMI) was calculated according to the formula weight $(\mathrm{kg}) /$ height $^{2}(\mathrm{~m})$, Blood Pressure (BP), Hemoglobin $(\mathrm{Hb})$, Fasting Blood Glucose (FBS) and Total Cholesterol (TC) in pregnant women (PW) in the three trimesters and in non-pregnant women (NPW). Sixty apparently healthy pregnant women and twenty non pregnant non lactating women (age range 17-34 years) participated in the study. The results showed significant difference in BMI of the pregnant women $\left(1^{\text {st }}, 2^{\text {nd }}\right.$, and $3^{\text {rd }}$ trimesters) and the control group $(p<0.05)$. There was an increase in BP levels in the pregnant women when compared to the non pregnant women. The results also showed that the levels of Hb decreased significantly $(p<0.05)$ as the pregnancy progressed through the three trimesters. However the results indicated that there was a significant increase $(p<0.05)$ in the FBS and TC levels between the non pregnant women and pregnant women through the trimesters.
\end{abstract}

Keywords: Pregnant women, non pregnant women, body mass index (BMI), blood pressure, hemoglobin, serum fasting blood glucose, total cholesterol.

\section{INTRODUCTION}

Women's nutrient needs increase during pregnancy and lactation. Some of the increased nutrient requirements protect maternal health while others affect birth outcome and infant health. If the requirements are not met, the consequences can be serious for women and their infants (Freedom from Hunger, 2003).

Anthropometry deals with measurements of body sizes and proportions. Such measurements when put against age (e, g weight for age and height for age) or against each other (e. g weight for height) can yield good indicators of nutritional status, International Institute for Tropical Agriculture (IITA, 2001). Unlike nutritional evaluation during other period of life which is concerned only with individual(s) in whom the measurements are made, measurements during pregnancy and lactation are expected to reflect both the nutritional status of the women and indirectly growth of fetus and later the quality and quantity of the breast milk (ACC/SCN, 1992).

Hyperlipiedaemia is a well known feature of pregnancy but the underlying cause for this change is not fully understood (Das and Isichei, 1996). A woman's risk for CHD increase if she has a total cholesterol level $>200 \mathrm{mg} / \mathrm{dl}$, Low density lipoprotein (LDL) cholesterol $>100 \mathrm{mg} / \mathrm{dl}$ and high density lipoprotein (HDL) cholesterol $<50 \mathrm{mg} / \mathrm{dl}$, or a triglycerides level $>150 \mathrm{mg} / \mathrm{dl}$ may also increase a woman's risk for CHD, Health Information for the public (HIP, 2001). Anemia refers to a condition in which blood has a lower than normal red blood cells (RBC) or when RBC don't contain enough Hemoglobin that may results in oxygen shortage of the blood, which increase heart's rate that may eventually raise the risk for CHD (HIP, 2001).
This study was motivated by the dearth of information on the nutritional status of pregnant women, especially in the rural areas of Kano State. Hence, this work was carried out to assess the nutritional status of pregnant women in General Hospital Kiru, Kiru Local Government Area of Kano State. The study specifically involved assessment of BMI, BP, hemoglobin and serum levels of FBS and total cholesterol.

\section{MATERIALS AND METHODS}

\section{Study Area}

The global location of Kano state is between longitude $08^{\circ} 30^{1}$ east of the Greenwich and also between latitude $11^{\circ} 30^{1}$ north of equator (Japheth, 2000). The state occupies an area approximately $60,473.2 \mathrm{~km}^{2}$ and has projected population of 9,401,288 (National Population Commission, 2006). Kiru Local Government is located within latitudes $11^{\circ} 20^{1} \mathrm{~N}$ to $11^{\circ} 45^{1} \mathrm{~N}$ and longitude $7^{\circ} 58^{1} \mathrm{E}$ to $8^{\circ} 16^{1} \mathrm{E}$. It covers an area of $1000 \mathrm{~km}^{2}$ and going by the 2006 population census the area is inhibited by 264,781 peoples (Abdullahi, 2007). Study Subjects

A total of 80 apparently healthy women (age range; 17-34 years) attending ante-natal clinic and outpatient department of Kiru General Hospital participated in the study, out of which 60 were PW and 20 were NPW (control group). Subjects were informed and their consent was sought and were then asked to come in the morning after an overnight fast of at least 12-14 hours.

\section{Sample Collection}

About $10 \mathrm{ml}$ of blood was drawn from anticubital vein after aseptic measures. 1cc blood was used to estimate hemoglobin. Serum was separated from the rest of the blood samples, and was used to estimate $\mathrm{TC}$ and FBS. For test involving serum, as much as possible, samples were analyzed on the day of collection. 


\section{Anthropometric Measurements}

Body weight of subjects was measured without shoes, in light closing, with the use of portable bathroom scale to the nearest $0.1 \mathrm{~kg}$, height was measured using a vertical measuring rod constructed with a non-stretchable tape firmly attached, with subjects standing bare footed, erect and heels put together as described by WHO, (1995).

\section{Blood Pressure Measurements}

The BP of the participants was measured using a stethoscope and sphygmomanometer.

\section{Biochemical Measurements}

Hemoglobin, Serum FBS and TC were estimated using Monica, (2003), glucose oxidase Trinder, (1969) and Zlatkis et al., (1953) methods respectively.

\section{Statistical Analysis}

Data were analyzed using ANOVA and $(p<0.05)$ was considered as statistically significant.

\section{RESULTS}

Mean age was found to be $24 \pm 5.4$ years for PW in their $1^{\text {st }}$ trimester, $21 \pm 3.6$ years for those in the $2^{\text {nd }}$ trimester, $22 \pm 3.1$ years for those in the $3^{\text {rd }}$ trimester and $25 \pm 4.3$ years for NPW. In the whole study group, the age ranges from 17 to 34 years, their height ranges from 1.45 to 1.80 meters, their weight ranges from 36 to 63 kilograms, BMI ranges from 15 to 25 $\mathrm{kg} / \mathrm{m}^{2}$ and gestational age for the pregnant women range from 3 to 9 months.

Table 1 shows the distribution according to BMI range classification. The results showed that $47 \mathrm{PW}$ and 6 NPW have normal BMI, $8 \mathrm{PW}$ and $12 \mathrm{NPW}$ are in grade 1 underweight, with only $2 \mathrm{PW}$ that fell under grade 2 underweight and none from others. Similarly, 2 PW are in grade 3 underweight with none from others. One PW and 2 NPW were in the grade 1 overweight, with none from others. None was recorded for both grade 2 and 3 overweight.

Table 3 shows the distribution of BMI, $\mathrm{Hb}, \mathrm{BP}, \mathrm{FBS}$ and TC among the subjects under study. PW in the $3^{\text {rd }}$ trimester group have higher value of mean BMI while the control group has the lowest. Highest mean value of $\mathrm{Hb}$ was obtained in the control group, on the other hand the values declined from the $1^{\text {st }}$ trimester through the $3^{\text {rd }}$ trimester. The mean BP value was found to be highest in the $3^{\text {rd }}$ trimester and declined through the $2^{\text {nd }}$ trimester, $1^{\text {st }}$ trimester and the control group. Mean Fasting Blood Glucose was also found to be highest in the $3^{\text {rd }}$ trimester group followed by $2^{\text {nd }}$ trimester group and the $1^{\text {st }}$ trimester with lowest mean value in the control group. Likewise, highest mean value of Total Cholesterol was obtained in the $3^{\text {rd }}$ trimester group with lowest value in the $1^{\text {st }}$ trimester.

\begin{tabular}{|c|c|c|c|c|c|}
\hline BMI Range & $\begin{array}{l}\text { PW } \quad 1^{\text {st }} \\
\text { Trimester }\end{array}$ & $\begin{array}{l}\text { PW } 2^{\text {nd }} \\
\text { Trimester }\end{array}$ & $\begin{array}{l}\text { PW } \\
\text { Trimester }\end{array}$ & $\begin{array}{l}\text { Non Preg } \\
\text { Women }\end{array}$ & Grade \\
\hline$<16.00$ & 0 & 1 & 1 & 0 & Grade 3 UW \\
\hline $16.00-16.99$ & 1 & 0 & 1 & 0 & Grade 2 UW \\
\hline $17.00-18.49$ & 3 & 5 & 0 & 12 & Grade 1 UW \\
\hline $18.50-24.99$ & 16 & 14 & 17 & 6 & Normal \\
\hline $25.00-29.99$ & 0 & 0 & 1 & 2 & Grade $1 \mathrm{OW}$ \\
\hline $30.00-39.99$ & 0 & 0 & 0 & 0 & Grade 2 OW \\
\hline$\geq 40$ & 0 & 0 & 0 & 0 & Grade 3 OW \\
\hline
\end{tabular}

Key: PW = Pregnant Women, BMI = Body Mass Index, UW = Underweight, $\mathrm{OW}=$ Overweight

Table 3: Mean BMI, Hemoglobin, Serum Fasting Blood Glucose, Blood Pressure and Total Cholesterol levels in Pregnant and Non Pregnant Women

\begin{tabular}{llllll}
\hline $\begin{array}{l}\text { Pregnant } \\
\text { Women } \\
(\mathbf{N}=\mathbf{2 0})\end{array}$ & BMI $\mathbf{( k g / \mathbf { m } ^ { 2 } )}$ & $\begin{array}{l}\text { Glucose } \\
(\mathbf{m m o l} / \mathbf{I})\end{array}$ & $\mathbf{B P} \mathbf{( \mathbf { m m H g } )}$ & $\mathbf{T C}(\mathbf{m g} / \mathbf{d l})$ & $\mathbf{H b}(\mathbf{m g} / \mathbf{d l})$ \\
\hline $1^{\text {st }}$ Trimester & $20.73 \pm 2.24$ & $5.95 \pm 3.40$ & $103.00 \pm 9.65 / 64.00 \pm 11.20$ & $155.7 \pm 21.20$ & $11.29 \pm 1.08$ \\
$2^{\text {nd }}$ Trimester & $20.33 \pm 2.18$ & $6.96 \pm 1.20$ & $104.50 \pm 10.99 / 60.50 \pm 10.37$ & $171.7 \pm 25.90$ & $11.04 \pm 0.89$ \\
$3^{\text {rd }}$ Trimester & $21.82 \pm 2.59$ & $7.80 \pm 2.40$ & $106.00 \pm 10.83 / 64.25 \pm 11.62$ & $173.8 \pm 15.00$ & $10.78 \pm 0.81$ \\
Non Pregnant & $19.38 \pm 2.36$ & $5.30 \pm 2.30$ & $102.50 \pm 11.10 / 63.50 \pm 14.70$ & $166.9 \pm 20.50$ & $11.38 \pm 1.24$
\end{tabular}

Women

Key: Results are presented as Mean \pm Standard Deviations (SD), $\mathrm{N}=$ Number of subjects, BMI = Body Mass Index, $\mathrm{BP}=$ Blood Pressure, $\mathrm{TC}=$ Total cholesterol, $\mathrm{Hb}=$ Hemoglobin

\section{DISCUSSION}

Maternal anthropometric status assessment during pregnancy reflects growth status (WHO, 1995). The mean BMI values (Table 2) indicates that NPW had the lowest value, which is significantly different when compared to compare to PW. These finding is in line with report of Law and Shiell, (1996) that the mean BMI values of the PW was significantly higher from that of the control group $(\mathrm{p}<0.05)$.
Normal pregnancy induced major alterations in carbohydrates, lipids and amino acids metabolism, hence plasma concentration of triglycerides, cholesterol, phospholipids and free fatty acids all increase during pregnancy (Damassceno, 2002). Our findings show that there is significant increase in TC of PW through the trimesters (table 2) when compared to NPW $(p<0.05)$. 
These agreed with the findings of Ekhator and Ebomoyi, (2012) that show increased TC of PW and opined that when this occurs along with high BP in pregnancy, it could to development of pre-eclampsia. Another study by Erica, (2011) reported that PW who had elevated TC levels were more likely to develop pregnancy induced hypertension.

In the PW group, the mean values of FBS was significantly higher (table 2 ) to that of the control group $(p<0.05)$. These are also in line with findings of Ekhator and Ebomoyi, (2012), which showed FBS levels to be higher in PW, and it is highest in the $3^{\text {rd }}$ trimester. These could be attributed to the fact that, the number of parity they had put them in the risk of developing gestational diabetes (GD). In Nigeria FBS level is said to be normal when it's between 3.3-5.5 $\mathrm{mmol} / \mathrm{l}$ (Attah, 2002). As can be seen from table 2, mean FBS of the PW $\left(1^{\text {st }}, 2^{\text {nd }}\right.$ and $3^{\text {rd }}$ trimester $)$ exceeded the normal range, hence these high sugar levels may be a sign of GD, AACC, (2012).

Iron deficiency is a major cause of anemia and the most prevalent nutrients deficiency among PW in developing countries (Choundhary et al., (2012). Our results also show that, mean hemoglobin levels of NPW were significantly higher, when compared to that of the PW group. From table 2, it can be seen that, in the PW group, hemoglobin level decrease with increasing duration of gestation, with the lowest peak in the $3^{\text {rd }}$ trimester. IMSCAG, (1992) report tally with

\section{REFERENCES}

AACC, American Association for Clinical Chemistry, 2012.

Abdullahi, I. T. (2007). Temporal Fluctuation of Underground Water Level and it is socioeconomic implications in Kiru, Kiru Local Government Area, Kano state. M. Sc Thesis. Geography Department. Bayero University Kano.

ACC/SCN, (1992). Second report of the world nutrition situation. Global and regional results (vol. 1) Geneva.

Attah, B. (2002). A Text Book of Pathology in Africa, $10^{\text {th }}$ edition. Bailliare Tindall. Elsevier Sanders Ltd. Pp. 662-671.

Choundhary, N. Aimone, A, Hyder, S. M. and Zlotkin, S. H. (2012). Severity of Anemia Increase with increasing gestational Age. Journal of Food Nutrition Bulletin. 33(2): Pp. 142-149.

Damassceno, D. C. (2002). Oxidative Stress and Diabetes in Pregnant Rats. Animal Reproductive Science. 72: pp. 235.

Das, S. C. and Isechei, U. P. (1996). Serum TOTAL Cholesterol, Beta Lipoprotien, triglycerides, HDL-Cholesterol and LDL-Cholesterol in Pregnant Nigerian Women. Tropical Journal of Obstetrics and Gynaecology. 13(1): 59-63.

Ekhator, C.N. and Ebomoyi, M. I. (2012). Lipid metabolic Change during Pregnancy. African Journal of Diabetes Medicine. 20(1): Pp. 110.

Erica, R. (2011). Higher Cholesterol and Insulin Levels in Pregnancy are associated with Increased these findings, in the report, it is stated that hemoglobin and hematocrit declined through the $1^{\text {st }}$ and $2^{\text {nd }}$ trimester, reaching lowest peak in the $2^{\text {nd }}$ to early in the $3^{\text {rd }}$ trimester. It is evident that, the significant declined of hemoglobin level in PW is due to in part to dietary iron deficiency, therefore iron therapy is helpful to maintain hemoglobin nearer to that of normal women (Waheed et al., 2008).

Systolic and diastolic BP of the PW group was also found to be significantly higher when compared to the control $(p<0.05)$, which is also in line with report of Law and Shiell, (1996), which show increase systolic and diastolic BP of the pregnant women group.

\section{CONCLUSION}

The study revealed that pregnant women (especially those in the $3^{\text {rd }}$ trimester) have higher BMI compared to the control group. However, all the values appeared normal, hence stunting $\mathrm{BMI}<16$ or obesity $\mathrm{BMI}>30$ were not recorded. BP, FBS and TC appear to increase with advancing pregnancy, which suggests the risk of gestational hypertension and diabetes.

\section{RECOMMENDATION}

Pregnant and non pregnant women should be educated on adequate healthy dietary intake to maintained normal height, weight, hemoglobin, BP, FBS and TC levels. Routine analysis of these parameters should be encouraged for all pregnant women at ante-natal clinics.

Risk for Pregnancy Induced Hypertension. www.livestrong.com/article/262409-c.

Freedom from Hunger, (2003). Women's Health: Healthy Women, Healthy Families. 10 learning sessions for group based education programs).

(www.univlillel.fr/pfeda/Ngonut/).

IITA, International Institute for Tropical Agriculture. (2001). Food Consumption and Nutrition Survey in Nigeria. Interviewer's manual. Pp 64-119.

IMSCAG, Institute of Medicine, Subcommittee for a Clinical Applications Guide. (1992).

Nutrition during pregnancy and lactation: an implementation guide. Washington: National Academy Press, Washington, DC

Japheth, A. (2000). African Atlases: Atlas of Nigeria. Les. Ed.

Law, C. M. and Shiell, A. W (1996). Is blood pressure inversely related to birth weight? Journal of Hypertension. 14: 935-41.

National Population Commission (2006). National Population in Nigeria. Federal Republic of Nigeria Official Gazette. B31.

Waheed, F., Latif, S., Uddin, M. and Mahmud, M. (2008). Megmensingh Medical Journal. 17(1): 4-7.

WHO (1995). Diabetes Mellitus. Report of WHO Expert Committee Geneva. Pp 99-360.

Zlatkis, A., Zak, B and Boyles, A.J. (1953). Serum Total Cholesterol Determination. Journal of Laboratory Clinical Medicine. 41: 486. 